\title{
Prazer e sedução
}

Heloísa Carneiro*

Sônia Helena Tlusty Furlanetto**

\section{RESUMO}

As autoras buscaram identificar qual o perfil e os meios utilizados pelos paulistanos quando pretendem conquistar alguém. Foram distribuídos e aplicados 80 questionários para pessoas de ambos os sexos na área metropolitana de São Paulo, obtendo-se os seguintes resultados:

- Para 58\% dos pesquisados o poder da sedução é inato; $62 \%$ acreditam que a sedução não acaba com o tempo. 68,96\%, consideram o jogo da conquista mais prazeroso do que a própria conquista. $50 \%$ dos pesquisados gostam de ser paquerados e $51,7 \%$ acreditam que os homens são mais paqueradores. Em relação a pessoa na condição de "conquistador", 23,5\% demonstraram maior preocupação com a aparência física, porém na

* Psicóloga e Terapeuta sexual; Diretora de relações sociais do CEPCoS.

* Psicóloga e Orientadora Sexual: Diretora de atividades didáticas e internas do CEPCoS Recebido em 10.08 .98 Aprovado em 20.08.98 
condição de "conquistados", $37,2 \%$ valorizam mais as características de personalidade do conquistador. $\mathrm{O}$ meio mais utilizado para seduzir é a comunicação, sendo que para 36,6\% dos entrevistados a comunicação não verbal é a mais importante. $64 \%$ das pessoas disseram sentirem-se seguras no relacionamento com um sedutor.

Concluímos que o jogo da sedução é mais valorizado do que a formação de vínculo com o seduzido e que a comunicação não verbal é fator relevante e importante no processo de sedução.

\begin{abstract}
The authors tried to identify the profile and the ways utilized by Brazilians when they intend to seduce someone. Eighty questionnaires were distributed to both (men and women) within the metropolitan area of São Paulo.

The results were:

- $58 \%$ believe that the power of seduction is innate,

- $62 \%$ believe that it never ends as the time goes by,

- $68,96 \%$ believe that the game of seduction is more pleasurable than the conquest itself,

- $50 \%$ prefer to be seduced than to seduce someone.
\end{abstract}

believe that men are more "lady-killer" the women are. Within this condition or denomination, 23,5\% men show more worries towards their physical appearance.

- However, when men are under the condition of being seduced by a woman. $37,2 \%$ of them believe that characteristics as personality is more appreciated by woman.

- $36,6 \%$ of the interviewees believe that the non-verbal communication is more utilized within the game os seduction

- The interviewees consider that the sexual involvement is due to physical attraction $(25 \%)$ than emotional factors.

- $64 \%$ of the interviewees feel themselves secure in a relationship with a seducer. 
The conclusion of this research, shows that the game of seduction is more important than to keep a link with the seduced persons and the way more utilized by the interviewees is the non-verbal communication.

\section{INTRODUÇÃO}

O estudo da sedução foi buscado pelas autoras para identificar aspectos comportamentais dos brasileiros quando pretendem conquistar uma pessoa e quais as possibilidades de obtenção de prazer, através do ato de seduzir e ser seduzido.

$\mathrm{O}$ interesse surgiu a partir do discurso que aparece freqüentemente no cotidiano assim como também no discurso científico e técnico da Psicologia e de que maneira alguns teóricos definem esse comportamento que tem sido tão estudado, entretanto na sua maioria por autores estrangeiros.

O estudo sobre o relacionamento humano é datado desde os primórdios da humanidade. Dentro do relacionamento inter-pessoal ganhou-se grande vulto nessas últimas décadas o interesse sobre a comunicação não verbal, lembrando que os orientais há séculos, utilizavam-se de características e movimentos faciais, num primeiro momento para a comunicação, e a partir da linguagem falada para a avaliação da personalidade.

Procuraremos descrever algumas maneiras utilizadas pelas pessoas quando tem a intenção de seduzir outra, e quais os componentes de personalidade das pessoas mais sedutoras, através de um questionário desenvolvido especificamente para estudar esse comportamento, e também através de uma entrevista com profissional masculino que trabalhou durante algum tempo no clube das mulheres e necessita do componente sedução, para encantar o seu público.

Descreveremos os aspectos físicos no contexto da sedução, investigaremos se quando uma pessoa está na posição de sedutor apresenta o mesmo interesse quando encontra-se na posição inversa (de seduzido), e se suas ações e expectativas em relação ao outro chegam a um denominador comum ou se existe discrepância em relação as ações das pessoas.

No processo da relação inter-pessoal procuraremos destacar nessa pesquisa a sincronicidade que está ligada diretamente ao processo de sedução, e que contribuem para o entendimento das mensagens transmitidas através da postura corporal e da orientação que se posicionam os corpos entre si. A postura corporal, a orientação corporal, formas de movi- 
mento e distância inter-pessoal são aspectos fundamentais os quais são carregados de informações sobre os relacionamentos.

Também descreveremos nessa pesquisa a importância da linguagem verbal, que será destacada para determinados tipos de personalidade, as quais encontram maior facilidade em comunicarem-se verbalmente obtendo sucesso no processo da sedução.

Existe também um outro comportamento peculiar das pessoas que tem essa facilidade de falar bem, que é o poder do convencimento através da fala.

Finalmente enfocaremos a pessoa que encontra-se na posição de seduzido e suas peculiaridades de comportamento, o que acreditamos revela certo potencial de sedução.

\section{DEFINIÇÃO}

SEDUÇÃO: (do latim (Seductione) S.F. 1 - Ato ou efeito de seduzir ou ser seduzido. Sin. (p. us). seduzimento 2 - Qualidade de sedutor. 3 Atração, encanto, fascínio. 4 - Bras. jur. Crime consistente em iludir mulher virgem, maior de 14 anos e menor de 18 anos, valendo-se da sua inexperiência ou justificável confiança para manter com ela conjunção carnal.

SEDUTOR: (ô). (Do latim seductore) Adj. 1 - Que seduz, atrai ou encanta. 2 - Aquele que seduz. 3 - Indivíduo que se aproveita de uma mulher por sedução (4).

SEDUZIR: (Do latim seducere, levar para o lado) V.t.d. 1 - Inclina artificiosamente para o mal ou para o erro; desencaminhar. Os prazeres seduzem muitos homens. 2 - Enganar ardilosamente. 3 - Desonrar, recorrendo a promessas, encantos ou mavios: Seduziu a menor. 4 - Atrair, encantar, fascinar, deslumbrar: Bela e culta, seduz quantos a conhecem; "Ele (Charles Dickens) adorava o teatro e nada o seduzia mais do que a idéia de se tornar um profissional da ribalta." (Eugenio Gomes, "Espelho contra espelho", p. 202). 5 - Levar a rebelião; revoltar, sublevar. 6 Subornar para fins sediciosos. (Irreg. Conj.: v. aduzir)

SEDUZÍVEL: Adj. 2g. Que pode ser seduzido.

ATRAIR: (Do latim Attrahere.) V.t.d. 1 - Trazer para si, puxar solicitar para sí; exercer atração sobre: Sua simpatia e bondade atraem todos o que dele se aproximam. 2 - Exercer atração sobre; Seduzir, fascinar, pren- 
der.- "A loucura o atraiu sempre, como tema complexo.- (Antonio Carlos Vilaça, "O desafio da liberdade", p. 20); A vida do mar o atraiu. 3 Chamar, incitar a aproximar-se: "Seu choro atraiu um guarda civil, que a conduziu até a delegacia." (Dalton Trevisan, "O vampiro de Curitiba", p. 76); Usou o pio para atrair a ave; Assobiou para para atrair a garota que passava. 4 - Provocar, mover, suscitar (opiniões, sentimentos etc.) T. d. ei. 5 - Fazer aproximar; trazer, puxar: "Abrindo a blusa, despi o porta-seios, atraí para mim sua cabeça com as duas mãos." (Osmã Lins, "Nove, novena”, p. 66). 6 - Fazer aderir (a opinião, religião, partido etc.): Tudo fizeram para atraí-lo ao catolicismo; Atraí-o para minha tese. 7 - Provocar, mover, suscitar: Conseguiu atrair estima e respeito para a sua pessoa Int. 8 Exercer atração, sedução, encantamento.- "É esbelta como o ideal da formosura de então sonhava; e tem o raro, o estranho que perturba, atrai, conquista." (Antero de Figueiredo, "Leonor Teles", p. 37) (Irreg. Conjug.: v. sair).

\section{MATERIAL E MÉTODOS}

Foram entregues 15 questionários pilotos, sendo que desses questionários, 4 (quatro) foram entregues à mulheres para que essas aplicassem à seus parceiros. Uma delas fez o seguinte comentário a pesquisadora: "Nossa, não sei se ele irá responder ao questionário!" Por quê? "Porque é difícil!" Outra pessoa comentou o seguinte: "Não sei' se entrego ou não este questionário!" Cinco questionários foram distribuídos entre adolescentes menores de 25 anos, e outros 5 foram distribuídos entre maiores de 25 anos. Solicitamos que os mesmos fossem devolvidos devidamente preenchidos o mais breve possível, entretanto não foram respondidos tampouco devolvidos.

Nos primeiros resultados colhidos através do material piloto assim como abstinência dos mesmos, pudemos constatar uma certa resistência por parte dos pesquisados (não apenas por aqueles que não foram devolvidos, mas também pela demora daqueles que foram respondidos) em responder os mesmos. Lembramos que desses 15 questionários, apenas $30 \%$ do total foram devolvidos. Diante disso acreditamos que a palavra sedução possivelmente fosse um fator relevante e provocador de inibição em nossos pesquisados. A partir desse dado, concluímos que eram necessárias certas mudanças para não invalidarmos a pesquisa. Fizemos uma consulta no dicionário Aurélio, buscando os sinônimos existentes na língua 
portuguesa para a palavra sedução. A partir das modificações no questionário este passou a ser bem recebido pelas pessoas e respondidos.

Foram aplicados 80 questionários (em anexo) para pessoas de ambos os sexos entre 20 à 67 anos de diferentes classes sociais, grau de instrução, situação financeira e parceria sexual na área metropolitana de São Paulo.

\section{CARACTERIZAÇÃo DA POPULAÇÃo}

\section{Gênero:}

masculino: $34,4 \%$

feminino: $65,51 \%$

\section{Estado Civil:}

casado: $58 \%$

solteiro: $27,5 \%$

outros: $13,7 \%$

\section{Escolaridade:}

superior: $55,17 \%$

$2^{\circ}$ grau: $31 \%$

$1^{\circ}$ grau: $10,34 \%$

não responderam: $3,44 \%$

\section{RESULTADOS}

Para $70 \%$ dos pesquisados a atração física é o aspecto mais importante seguido de $23,3 \%$ do aspecto vínculo afetivo, 6,66\% responderam que existem outros aspectos importantes para que seja estabelecido vínculo afetivo.

Para 58,62\% o encanto pessoal é inato e para $34,48 \%$ é um comportamento aprendido, sendo que $3,44 \%$ responderam que o encanto pessoal é inato embora seja melhor elaborado com o decorrer do tempo. Para $62 \%$ dos pesquisados uma pessoa que é sedutora sempre será, e para $34,48 \%$ esse poder se perderá no decorrer do tempo. 
Para 68,96\% o mais fascinante é o processo da conquista do que o objeto da mesma. E para $24,13 \%$ o objeto da conquista é mais importante.

$50 \%$ dos nossos pesquisados responderam que gostam de ser paquerados e $18,18 \%$ responderam que sentem-se envaidecidos.

Para 36,6\% dos pesquisados a comunicação não verbal é o fator que mais chama atenção numa situação de paquera.

Para $30 \%$ os aspectos físicos são os fatores importantes numa situação de paquera e para $16,66 \%$ a comunicação verbal é colocada como o fator mais importante, ou seja nada como um bom diálogo numa situação de paquera.

Para 51,7\% os homens são mais paqueradores que as mulheres.

Dos nossos pesquisados $37,2 \%$ valorizam as características de personalidade como sendo o aspecto mais atrativo numa pessoa.

Para $23,5 \%$ a aparência física é fator fundamental para paquerar embora o fator mais importante verificado nessa pesquisa foi o aspecto não verbal da comunicação $41,17 \%$.

$64,51 \%$ o dos nossos pesquisados se consideram pessoas atraentes.

$64 \%$ dos nossos pesquisados se consideram seguros se relacionando com uma pessoa sedutora.

$25 \%$ dos nossos pesquisados responderam que sexo está relacionado com a atração física sendo que outros $25 \%$ responderam que existem outros aspectos para ocorrer um relacionamento sexual os quais não foram especificados nessa pesquisa.

\section{DISCUSSÃO}

O estudo sobre o comportamento de sedução foi buscado pelas autoras para que conhecessem as formas e o perfil de uma pessoa sedutora dentro da nossa cultura.

A relevância dos aspectos físicos no contexto da sedução foi observada através dos resultados da pesquisa, onde se constata uma grande discrepância entre as citações das pessoas a respeito da importância que dão aos aspectos físicos do outro e suas ações e expectativas em relação ao outro.

Entretanto vamos encontrar nos estudos de Knapp (citado por Silva, 1987), a afirmação de que as pessoas fisicamente atraentes são favoravelmente avaliadas em uma ampla gama de características socialmente desejáveis, tais como êxito, personalidade, popularidade, sociabilidade, personalidade e até mesmo a felicidade. 
Outro aspecto interessante verificado nessa pesquisa é a sincronicidade onde vários autores construíram para o aprimoramento do entendimento das mensagens transmitidas através da postura corporal, também da orientação corporal, ou seja, as formas de se movimentar frente a um indivíduo ao qual se pretende chamar a atenção e posteriormente seduzir. Também a distância interpessoal são considerados aspectos fundamentais que vem carregados de informações sobre os anseios e os relacionamentos das pessoas.

A necessidade de aproximação física identificada na pesquisa em questão, vai encontrar apoio teórico nas obras de Hall (citado por Silva, 1987).

Outro fator levantado pelos teóricos e confirmado nesse estudo são os que dizem respeito às expressões faciais das emoções durante o processo de sedução. Alguns sinais corporais são observados, tais como: pupilas dilatadas, olhos mais brilhantes e com mais vivacidade, entumescimento da parte inferior dos lábios, a bochecha torna-se mais rosada. Geralmente no caso das mulheres, estas costumam jogar para traz a cabeça, e mexer com mais freqüência os cabelos. Estes são alguns dos muitos sinais observados pelos pesquisadores e que podem ser caracterizados como a existência de interesse e disponibilidade para desenvolver um relacionamento afetivo por alguém.

A comunicação não verbal tão valorizada nesta pesquisa está intimamente interligada ao jogo de sedução (que aparece como sendo um dos fatores de grande importância no jogo da sedução). O fascínio do olhar, a maneira de mover o corpo e o sorriso, leva as pessoas a saborearem o prazer no comportamento da sedução.

Segundo Silva (1987), o flerte é uma negociação à distância e o jocoo da sedução obedece à uma seqüência que deve ser cumprida passo a passo; trata-se de um ritual.

Segundo Sibony (s/d), "A sedução e o sacrifício são duas abordagens ritualizadas do inconsciente".

Pelo sacrifício tentamos seduzir o outro; pela sedução, deixamo-nos tentar ser a perda que lhe falta para desejar, a perdição que nos deixa ali a desejar: organizamos um sacrifício em torno do outro a quem falta ser, para fazê-lo ser e desaparecer ao mesmo tempo.

De sorte que em certo sentido não "resistimos" à sedução; podemos rejeitála, cristalizar a distância que ela manipula, mas "resistir" já é entrar em contato com ela e manter intacta sua possibilidade, sua iminência não manipulável e presente. 
A simpatia, a naturalidade, o encanto, a gentileza, a educação (boas maneiras) e o caráter, são as características mais importantes, consideradas pelos entrevistados, para se estabelecer um vínculo afetivo.

A maioria dos entrevistados responderam que os homens são mais paqueradores do que as mulheres, que estes exercem com maior facilidade e que tem mais habilidades para conquistar. Isto pode ter influência da nossa cultura que por ser machista espera que o sexo masculino tenha um comportamento mais ativo que as mulheres. Lembrando que não apenas percebemos esse componente comportamental nos seres humanos, já que podemos observar comportamentos semelhantes também em outras espécies animais.

O fator sócio-econômico-cultural, apesar de relevante num processo de escolha do outro, não atinge muito as pessoas do sexo feminino, que podem ser privilegiadas quanto a esse aspecto; em contrapartida será cobrado dela uma aparência física mais próxima dos padrões estéticos de beleza da nossa cultura, e o fator de poder aquisitivo menor, ou menor cultura pouca influência exercerá sobre elas, não as impedindo de serem escolhidas por um pretendente, Porém no que se refere ao sexo masculino, será cobrado maior poder aquisitivo, intelectual e social.

Os resultados desta pesquisa evidenciam que a maioria das pessoas gostam ser paqueradas. Isto pode ser explicado segundo o estudo de Silva (1987) que afirma que durante o flerte as pessoas ficam mais bonitas, mais jovens, mais felizes, o que consequentemente as deixarão mais saudáveis.

$\mathrm{Na}$ literatura sobre a sedução encontramos referência ao perfil de atuação dos sedutores. ( "A sedução e suas máscaras”, 1988). Uma delas é a chamada "lábia irresistível", que consegue transformar a frieza do cálculo, a precisão e a velocidade de raciocínio em emoção no com da voz, a no brilho tocante das palavras. Muitas pessoas sedutoras não amam aquelas que seduzem, amam a sedução, tanto isso é verdadeiro que tão logo bem sucedida é a sedução por uma pessoa, o seduzido cairá no desinteresse e novas conquistas ocorrerão.

Outro perfil de atuação de sedução é aquele em que a pessoa sedutora não age, posa, ao invés de conquistar é conquistado, no arriscar com o outro, será disputado e protegido por todos aqueles que desejam seduzi-lo. "Esse sedutor é uma pessoa geralmente jovem, linda, fina, esbelta, graciosa, bondosa, culta e devota...", um anjo caído do céu, uma imagem sedutora, que através do ritual de ser seduzido é quem seduz.

Não se pode prever quando uma sedução começa; além de intransitive, a sedução é atípica e indefinida. 


\section{CONCLUSÕES}

As autoras concluíram que a sedução pode manifestar-se de diversas formas, graus e situações diferentes, independente da idade, sexo, nível social, cultural ou beleza física, a atração principal está no jogo de seduzir ou ser seduzido.

Em geral o(a) sedutor(a) é uma pessoa com bom nível de inteligência, alto grau de socialização e com bom diálogo, sendo considerada popularmente como uma pessoa de "boa lábia". É um grande observador do ambiente, elabora suas ações com rapidez de pensamento, buscando nesta observação calcular precisamente o comportamento da pessoa que esta pretendendo seduzir, sem cometer erros.

Na sedução se revela um excelente jogador, procura nos parceiros comportamentos semelhantes, ou seja, um 'Jogador a sua altura".

Para seduzir, a pessoa sedutora se utilizará de vários recursos, sempre de acordo com a situação, agindo matematicamente. A arte de seduzir faz do seu protagonista, um ator convincente, tão real nas representações de seus personagens, com máscaras adequadas para cada ocasião.

Dentre os comportamentos mais freqüentes utilizados pela pessoa sedutora estão: A expressão corporal (muito explorada pelo sedutor), o jogo do olhar, a exposição proposital de partes do corpo, a sincronicidade calculada e todos os outros comportamentos que são identificados na literatura como sendo não verbais. O uso de perfumes, maquilagens, jóias, boas vestimentas fazem parte do ritual no processo de sedução.

Os aspectos físicos são tão importantes quanto os aspectos de personalidade para seduzir ou ser seduzido, entretanto quando a pessoa está na posição de seduzida irá se preocupar muito mais com os aspectos de personalidade do sedutor.

O sedutor é uma pessoa que tem um amor próprio exacerbado onde a autovalorização dos aspectos positivos estarão sempre presenter. É confiante no seu poder de sedução, o que contribuíra para o ato se concretizar.

Os fatores sócio-culturais tem um peso de destaque na escolha da pessoa que o sedutor pretenderá seduzir.

Concluímos também que o jogo da sedução para o sedutor será mais importante que o objeto da conquista, tanto que quando este atinge seu objetivo, o seduzido perderá o encanto e novas conquistas acontecerão. 
O sedutor é objetivo naquilo que pretende, ou seja, seduzir uma pessoa, uma posição de destaque, e etc., porém no decurso das suas investidas é uma pessoa intransitiva.

Num grau mais elevado a sedução pode tornar-se algo negativo tanto para o seduzido, quanto para o próprio sedutor, sendo considerado por alguns teóricos como um Comportamento compulsivo.

A sedução é um comportamento paliativo pare a não frustração e necessário para a nossa sobrevivência, desde que haja limites, ética a respeito pelas pessoas.

\section{REFERÊNCIAS BIBLIOGRÁFICAS}

1. BARTHERAT, T.; CAROL B. O corpo tem suas razões. Ed. Martins Fontes, 1995.

2. CABRAL e NICK. Dicionário técnico de psicologia. Ed. Cultrix, 1974, São Paulo.

3. CARNEIRO, Heloisa LL.; LERNER, Théo; RODRIGUES JR. O. M.; VACCARI, Vera. As preocupações da mulher adolescente. São Paulo, 1996. DAVIS, F. A comunicação não verbal.

4. FERREIRA, A. B. de H. Novo Dicionário Aurélio da Língua Portuguese. Ed. Nova Fronteira, Rio de Janeiro, 1996.

5. FURLANETTO, S. H. T.; RODRIGUES JR., O. M. A satisfação da mulher adulta. Revista Científica da UNG, número Ol, ano 01, 1996 e Revista Bras. de Sexualidade Humana, 1996.

6. FURLANETTO, S. H. T.; RODRIGUES JR., O. M. Exibicionismo entre as mulheres brasileiras. Apresentado no VIII Congr. Latinoamericano de Sex. Humana, Montevidéu, Uruguay, 1996.

7. JOHNSON, R. A. He. A chave do entendimento da psicologia masculina. Ed. Mercuryo, São Paulo, 1987.

8. LAPLANCHE e PONTALIS, Vocabulário de psicanálise. Ed. Moraes, 1977.

9. OLIEVENSTEIN, C. O não dito das emoções. Jorge Zahar Editor, Rio de Janeiro, 1989.

10. RIBEIRO, R. R. Nos laços da sedução. Ed. Pereira de Castro, São Paulo, 1995.

11. SIBONY, Daniel. Sedução - o amor inconsciente. Editora Brasilense.

12. SILVA, A. A. A comunicação não verbal.

13. WEIL, P. Amar e ser amado - a comunicação no amor. Editora Vozes, 1997.

14. PROGOFF, I. Jung, sincronicidade e destino humano. A teoria da coincidência significativa de C. G. Jung. Editora Cultrix, 1973. 


\section{REFERÊNCIAS DIVERSAS}

- Filme: Dom Juan de Marco.

- Filme: Excalibur.

- Programa: Globo Repórter. Exibido em 27.02.98.

- Filme: Sedução Fatal.

- Filme: Sedução.

\section{Anexo \\ QUESTIONÁRIO}

Estamos interessados em conhecer aspectos comportamentais dos brasileiros. Trata-se de um questionário piloto, e não existem questões certas, existe a opinião de cada um. Não é necessário se identificar. Obrigado.

Sexo: ( ) masc. ( ) fem.

Idade:

Est. Civil: ( ) solt. ( ) casado ( ) desquit. ( ) parceria fixa ( ) outros.

Escolaridade: ( ) $1^{\circ}$ grau ( ) $2^{\circ}$ grau ( ) superior, qual

Profissão:

1) Qual a importância da atração física, para se estabelecer vínculos afetivos?

2) O encanto pessoal é:

( ) inato ( ) comportamento aprendido

3) Uma pessoa que é cativante, sempre será?

( ) $\operatorname{sim}$ ( ) não

4) O que eu acho mais fascinante:

( ) a conquista ( ) objeto da conquista 
5) Como me sinto, quando percebo que estou sendo paquerado?

( ) Envaidecido

( ) Sinto-me bem

( ) Totalmente sem defesa
( ) Não me sinto bem

( ) Fico constrangido

( ) Outros. Quais?

6) Se uma pessoa estiver me paquerando (flertando), o que ela precisa ter, para que eu retribua o flerte?

7) Na minha opinião quem é mais conquistador?

( ) homem ( ) mulher

8) O que eu acho mais atraente numa pessoa?

9) O que eu faço para atrair alguém que me interessa?

10) Me considero uma pessoa atraente? Por que?

11) Me sinto seguro, quando me relaciono com uma pessoa sedutora?

( ) $\operatorname{sim}($ ) não

12) Sexo na minha opinião está relacionado à:
( ) deslumbramento
( ) paixão
( ) fascinio
( ) atração
( ) desejo
( ) prazer
( ) outros: 